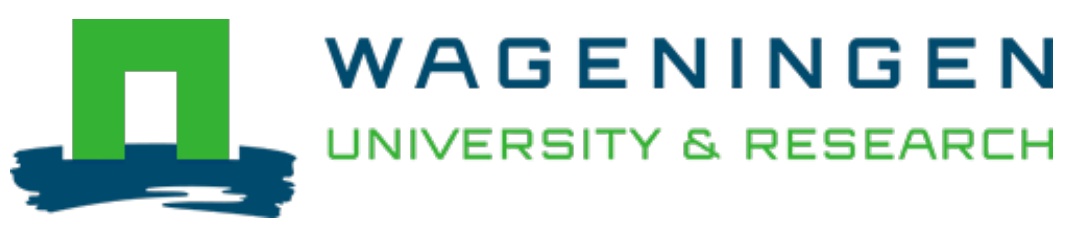

\title{
Differential ecological filtering across life cycle stages drive old-field succession in a neotropical dry forest
}

\author{
Forest Ecology and Management \\ Martínez-Ramos, Miguel; Barragán, Felipe; Mora, Francisco; Maza-Villalobos, Susana; Arreola-Villa, Luis F. \\ et al \\ https://doi.org/10.1016/j.foreco.2020.118810
}

This publication is made publicly available in the institutional repository of Wageningen University and Research, under the terms of article $25 \mathrm{fa}$ of the Dutch Copyright Act, also known as the Amendment Taverne. This has been done with explicit consent by the author.

Article 25 fa states that the author of a short scientific work funded either wholly or partially by Dutch public funds is entitled to make that work publicly available for no consideration following a reasonable period of time after the work was first published, provided that clear reference is made to the source of the first publication of the work.

This publication is distributed under The Association of Universities in the Netherlands (VSNU) 'Article 25fa implementation' project. In this project research outputs of researchers employed by Dutch Universities that comply with the legal requirements of Article $25 \mathrm{fa}$ of the Dutch Copyright Act are distributed online and free of cost or other barriers in institutional repositories. Research outputs are distributed six months after their first online publication in the original published version and with proper attribution to the source of the original publication.

You are permitted to download and use the publication for personal purposes. All rights remain with the author(s) and / or copyright owner(s) of this work. Any use of the publication or parts of it other than authorised under article $25 \mathrm{fa}$ of the Dutch Copyright act is prohibited. Wageningen University \& Research and the author(s) of this publication shall not be held responsible or liable for any damages resulting from your (re)use of this publication.

For questions regarding the public availability of this publication please contact openscience.library@wur.nl 


\title{
Differential ecological filtering across life cycle stages drive old-field succession in a neotropical dry forest
}

\author{
Miguel Martínez-Ramos a, , Felipe Barragán ${ }^{\text {a,b }}$, Francisco Mora ${ }^{\text {a }}$, Susana Maza-Villalobos ${ }^{\text {a,c,d }}$, \\ Luis F. Arreola-Villa ${ }^{a}$, Radika Bhaskar ${ }^{\mathrm{e}}$, Frans Bongers ${ }^{\mathrm{f}}$, Celina Lemus-Herrera ${ }^{\mathrm{g}}$, Horacio Paz ${ }^{\mathrm{a}}$, \\ Angelina Martínez-Yrizar ${ }^{\mathrm{h}}$, Bianca A. Santini ${ }^{\mathrm{a}}$, Patricia Balvanera ${ }^{\mathrm{a}}$ \\ ${ }^{a}$ Instituto de Investigaciones en Ecosistemas y Sustentabilidad, Universidad Nacional Autónoma de México, Antigua Carretera a Pátzcuaro 8701, 58190 Morelia, \\ Michoacán, Mexico \\ ${ }^{\mathrm{b}}$ CONACYT - Instituto Potosino de Investigación Científica y Tecnológica, División de Ciencias Ambientales, Camino a la presa San José 2055, Lomas 4ta Sección, \\ 78216 San Luis Potosí, S.L.P., Mexico

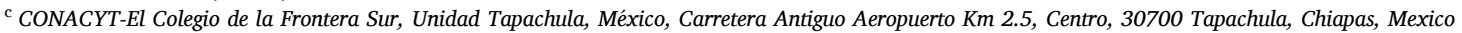 \\ ${ }^{\mathrm{d}}$ Escuela Nacional de Estudios Superiores Morelia, Universidad Nacional Autónoma de México, Antigua Carretera a Pátzcuaro 8701,58190 Morelia, Michoacán, \\ Mexico \\ ${ }^{\mathrm{e}}$ College of Design, Engineering, and Commerce, Thomas Jefferson University, Philadelphia, PA, USA \\ ${ }^{\mathrm{f}}$ Forest Ecology and Forest Management Group, Wageningen University, P.O. Box 47, 6700 AA Wageningen, the Netherlands \\ ${ }^{\mathrm{g}}$ Universidad Intercultural Indígena de Michoacán, Carretera Huecorio Km 3, 61614 Pátzcuro, Michoacán, Mexico \\ ${ }^{\mathrm{h}}$ Instituto de Ecología, Universidad Nacional Autónoma de México, Av. Colosio y Sahuaripa s/n, Hermosillo, Sonora 83250, Mexico
}

\section{A R T I C L E I N F O}

\section{Keywords:}

Chronosequence

Assembly mechanisms

Drought tolerance

Phylogenetic structure and diversity

Species replacement

Forest regeneration and management

\begin{abstract}
A B S T R A C T
Abiotic and biotic filters may play differential roles in the plant community organization along forest succession in abandoned fields. However, little is known about how life stage-specific filters influence species replacement during succession. We approach this issue by analyzing changes in community attributes (abundance, species density, species diversity, species composition) and the phylogenetic structure of shrubs and trees at different life stages during the old-field succession of a seasonally tropical dry forest (TDF) in Western Mexico. We raised two main questions: (1) How different are the trajectories of change in community attributes and phylogenetic structure along succession for shrub and tree species at different life-stages? (2) Do different stage-specific trajectories result from differential filtering mechanisms? We used a chronosequence of abandoned pastures and forest sites, classified in five successional categories (with three sites each): Pasture $(<1.5$ years fallow age), Early (3.5-5.5 y), Mid (6-8 y), Advanced (13-15 y), and Old-Growth Forest. Identity and abundance of species were recorded at five life stages: seeds in the top soil layer, seedlings (plants emerged from seeds, 10-100 cm height), resprouts (plants emerging from buds in roots or stumps, 10-100 cm height), juvenile [shrubs and trees $>100 \mathrm{~cm}$ height and $<2.5 \mathrm{~cm}$ diameter at breast height (DBH)], adults (shrubs and trees with DBH $\geq 2.5 \mathrm{~cm}$ ). Additionally, we quantified the phylogenetic mean parwise distance (MPD) among species, and analyzed the phylogenetic community structure, for each successional category and life stage. We found that early in succession the resprout stage was more abundant and diverse than the seedling stage, while the inverse occurred late in succession. Along the first 15 years of succession, the seedling stage showed a clumped phylogenetic structure (with a strong dominance of legume species), while the resprout stage tended to have an overdispersed one (with species from a wide range of clades). Also, community attributes of the juvenile and adult stages approached those of the old-growth forest, and in both stages the phylogenetic structure changed from clustered to random. Overall, our results suggest that the assembly of shrub and trees communities along succession resulted from a combination of abiotic filtering processes, operating mostly on seedlings (selecting primarily legume droughttolerant species), and biotic filtering processes, operating mostly in resprouts (generating a taxonomic and phylogenetically diverse regenerative pool). The implications of these results for the management of secondary TDF in human modified landscapes are discussed.
\end{abstract}

\footnotetext{
* Corresponding author.

E-mail address: mmartinez@cieco.unam.mx (M. Martínez-Ramos).
} 


\section{Introduction}

Understanding the mechanisms underlying secondary forest succession has historically been a central area of study in ecology (Cowles, 1911; Connell and Slatyer, 1977; Bazzaz, 1979; Finegan, 1984; Pickett et al., 1987). Such understanding is important for the advance of ecology as science per se, but also provides the bases for the management (conservation, restoration, and sustainable use) of forest ecosystems, their biodiversity, and their contributions to the wellbeing of people in human modified landscapes (Quesada et al., 2009; Chazdon 2014).

Some hypotheses propose that succession results from species being filtered depending on functional traits related to dispersal, survival, growth, and reproduction (Li et al., 2015; Arroyo-Rodríguez et al., 2017). Over the course of succession, changes in these trait-based filters are expected. One hypothesis proposes that abiotic filters may have a major role in determining the structure and composition of plant communities early in succession, while biotic filters (i.e., biotic interactions such as competition, predation, mutualism, diseases) increase in relevance late in succession (e.g., Letcher et al., 2012).

The relative importance of abiotic and biotic filters along succession can be inferred by assessing the evolutionary relatedness among species of a biotic community, an approach known as phylogenetic community analysis (Whitfeld et al., 2012; Li et al., 2015; Maza-Villalobos et al., 2020). Under the assumption that species conserve their niches and related ecological traits across space and times (i.e., niche conservatism concept), a clustered phylogenetic community structure (i.e., when species are more closely related than expected by chance) is suggestive of abiotic filters (Webb et al., 2002), whereas an overdispersed phylogenetic structure (i.e., when species are less related than expected by chance) could be indicative of the operation of biotic filters (Kraft and Ackerly, 2010; Götzenberger et al., 2012). The two types of filters can operate simultaneously, and can generate random phylogenetic structures (i.e., when phylogenetic distance among species are not different from that expected by chance; Cadotte and Tucker, 2017) along succession (Maza-Villalobos et al., 2020). Also, a random structure can be generated by stochastic processes (such as probabilistic seed dispersal) or by neutral assembly mechanisms (Hubbell, 2011; Stegen et al., 2012, Swenson et al., 2012).

While clustered phylogenetic structures can easily be attributed to the operation of abiotic filters (but see Cadotte and Tucker, 2017), overdispersed structures might not be attributable necessarily to biotic filters. For example, overdispersion will be observed as a result of abiotic filters if the relevant trait attributes arise repeatedly in distantly related species (Willis et al., 2010; Cadotte and Tucker, 2017). Also, environmental modification during succession generally decreases the strength of abiotic filtering and may increase the carrying capacity of the local habitat, which could facilitate the colonization of the species with different functional traits (Li et al., 2015). In such case, the increase of phylogenetic overdispersion during succession could result from the colonization of distant relatives, rather than from the operation of antagonistic biotic interactions, such as competition (Li et al., 2015; Maza-Villalobos et al., 2020).

Understanding the mechanisms structuring plant communities, specifically those driving secondary succession of tropical dry forests (TDF) in abandoned fields (i.e. old-field succession), is an open area of research (e.g., Lebrija-Trejos et al., 2010a; Chazdon et al., 2011). TDF occur in regions with low annual rainfall $(250-2000 \mathrm{~mm})$ and dry seasons with several months of duration (Bullock et al., 1995). It has been proposed that the low water availability and harsh microclimate conditions (e.g. high irradiance, temperature, and evaporative demands) prevailing early in TDF succession select for drought-tolerant species, particularly legumes with small leaflets in the neotropics (Lohbeck et al., 2015; Gei et al., 2018), and that biotic filtering become an important mechanism of community assembly later on succession, when shaded and humid environmental conditions appear in the understory during the rainy season (Lebrija-Trejos et al., 2010b, 2011; Maza-Villalobos et al., 2013;
Gei et al., 2018). A previous study (Bhaskar et al., 2014), conducted in the same TDF successional system we used in the present study, examined the range of variation in functional trait (specific leaf area, wood density, leaf nitrogen content) values among shrub and tree species at different successional stages, and while some evidence supported the shift of the relative importance of abiotic and biotic filters along succession, the effect of abiotic filtering in early stages was not consistently observed for all functional traits (but see Maza-Villalobos et al., 2020). The authors speculated this was in part due to the mix of remnant adult trees and resprouting individuals found in early stages. Thus, a better understanding of how abiotic and biotic filters operate on distinct life stages through the course of TDF succession is needed (Lai et al., 2009; Norden et al., 2009; Hu et al., 2012). Special attention is required for understanding the role of these filters on the two main recruitment strategies: resprouts and seedlings. Resprouts are an important source of TDF regeneration in abandoned fields and along succession, and could respond differently than seedlings to abiotic filters as resprouts are connected to large root systems (Poorter et al., 2010; Maza-Villalobos et al., 2013, 2020). Resprouts can result from legacies for the agricultural period, but also from the period before agricultural use, especially in recently opened-up forest areas (Jakovac et al., 2015).

In this study, we explored assembly mechanisms driving old-field TDF succession. Specifically, we analyze changes in community attributes (abundance, species diversity, composition) and the phylogenetic structure of shrub and tree species at different life stages (seed, seedling, resprout, juvenile, adult), across a chronosequence of abandoned cattle pastures and old-growth TDF sites in Western Mexico. We approach the following questions: 1) how different are the trajectories of change in community attributes and phylogenetic structure along succession for communities of tree and shrub species of different life stages? 2) Do different life-stage specific trajectories result from differential filtering mechanisms?

We predict abundance, species diversity, and species dissimilarity to increase as TDF succession unfolds as a result of strong abiotic filtering process (promoting high species similarity) in early stages, and an increasing role of biotic filters (promoting species dissimilarity) in later successional stages. For the different life stages, we predict strong abiotic filtering of species at the seed to seedling transition, especially during the first years of succession, when few closely related droughttolerant species are expected to establish successfully as seedlings. We also predict that species undergo a stronger abiotic filtering at the seedling than at the resprout stage, because resprouts have greater maternal resources than seedlings to cope with harsh environmental conditions. Consequently, under the assumption of niche and corresponding trait conservatism, we expect that the seedling stage will show higher phylogenetic clustering than the resprout stage, and that the phylogenetic structure will change from clustered to overdispersed as succession advances. Shifts in phylogenetic structure should be noted mostly in assemblages of the juvenile and adult stages, as they result from operation of filtering processes at earlier life stages (seed, seedling, resprout).

Given that TDF are widely distributed but severely threatened (Dexter et al., 2018; Powers et al., 2018), for management purposes (e. g., conservation of biodiversity and ecosystem functions and services, restoration, and sustainable harvesting of timber and non-timber forest products), it is fundamental to understand how TDF plant communities are structured along old-field succession (Quesada et al., 2009). Thus, in a final section, we discuss our findings in the context of their relevance for the management of TDF in human-modified landscapes (Mora et al., 2016; Fremout et al., 2020).

\section{Materials and methods}

\subsection{Study region}

The study region is located in the municipality of La Huerta, which 
includes the Chamela-Cuixmala Biosphere Reserve, in western Mexico $\left(19^{\circ} 29^{\prime} \mathrm{N}, 105^{\circ} 01^{\prime} \mathrm{W}\right.$; Fig. S1). The climate is warm and sub-humid, with a mean annual temperature of $25.6{ }^{\circ} \mathrm{C}$ and a mean annual rainfall of $800.4 \mathrm{~mm}$. There is a strong and long dry season (with virtually no rain) from November to May, and a wet season, normally between July and October (Maass et al., 2018). The dominant vegetation is seasonally tropical dry forest (mean canopy height around $8 \mathrm{~m}$ ), while medium size semi-deciduous tropical forest is found along the arroyos (Durán et al., 2002). Since the 1970s, the forest outside the reserve has been partially converted to agriculture. Today, the region is covered by a mixture of cattle pastures, crops, and secondary forests, although old-growth forests still cover $>50 \%$ of the region (Sánchez-Azofeifa et al., 2009; FloresCasas and Ortega-Huerta, 2019).

\subsection{Study system}

In October 2004, we established a chronosequence of nine abandoned cattle pasture sites (with $0-12$ years of abandonment) and three old-growth forest sites, across an area of about $100 \mathrm{~km}^{2}$ (Fig. S1). All sites were located in moderate south-facing slopes to control as much as possible for topographic differences in water and light availability among sites (Maza-Villalobos et al., 2011a). At each site, a permanent $20 \times 50 \mathrm{~m}(0.1 \mathrm{ha})$ plot was established. The plots are permanent and the vegetation within has been surveyed along time to accomplish different studies on TDF succession (e.g., Maza-Villalobos et al., 2011a, b, 2013, 2020; Mora et al., 2015). Although plots were small, and some rare species could have been missed, all plots were of same size, which enabled us to approach our questions and predictions.

We did take advantage of the repeated data gathered from the plots, to establish a chronosequence of five successional categories (with three plots each; see details in Table S1, supplementary information). These resulted in the following fallow ages (years): Pasture $(<1.5)$, Early (3.5-5.5), Mid (6-8), Advanced (A, 13-15), and Old-Growth Forest (OGF, forest sites without signs of human disturbance). In other studies, we have shown that our Advanced category shares similar structural and compositional attributes than the old-growth forest category, when considering regenerative plants $(\leq 1 \mathrm{~m}$ height; Maza-Villalobos et al., $2011 \mathrm{a}$,b) or stems $\geq 1 \mathrm{~cm}$ DBH of shrub and tree species (Mora et al., 2015).

We considered five life stages: seed in the top soil layer (hereafter "seed"), seedling (plants 10-100 cm height), resprout (plants with stems $10-100 \mathrm{~cm}$ height, emerged from older broken or cut stems or with roots clearly connected to other plants), small trees and shrubs [hereafter called "juveniles", plants with a height $>100 \mathrm{~cm}$ and a diameter at breast height $(\mathrm{DBH})<2.5 \mathrm{~cm}$ ), and large trees and shrubs (hereafter called "adult", $\mathrm{DBH} \geq 2.5 \mathrm{~cm}$ ). The last stage included both immature and mature adult plants, and even saplings in the lower DBH limit of this category. The resprout stage was included as a separate life stage due to their importance for forest regeneration in TDF (Vieira and Scariot, 2006) and to explore the operation of filters on them. Although shrubs (woody plants with several stems emerging from the ground) and trees (wood plants with a single stem at the ground level) differ in several aspects of their biology, studies conducted in our chronosequence system show that recruitment, survival and growth rates of small shrubs and trees behave similarly among successional categories in response to environmental conditions (Maza-Villalobos et al., 2013). This demographic similarity between shrubs and trees gives us confidence to group them in our analyses.

Our plots have been used to collect data from shrubs and trees using different sampling protocols. Data collection for each life stage varied as described below.

\subsubsection{Seed sampling}

In May 2005, twenty cylindrical soil cores $(10 \mathrm{~cm}$ diameter, $15 \mathrm{~cm}$ depth) were randomly taken in each one of our 12 studied plots (total sampling area of $0.16 \mathrm{~m}^{2}$ per plot) to sample seeds. This was done towards the end of the dry season, when the seed production and the abundance and diversity of the soil seed bank peaks (Bullock and SolísMagallanes, 1990; Grombone-Guaratini and Rodrigues, 2002; Martins and Engel, 2007). We separated seeds $\geq 1 \mathrm{~mm}$ in diameter by sieving and inspecting samples under a stereoscopic microscope. Seeds were separated into unequivocal morphospecies that were identified to the lowest taxonomic level whenever possible. Seeds of unidentified morphospecies were germinated in a greenhouse to obtain seedlings for taxonomical identification. Structural attributes and species composition per site were quantified for a lumped pool with all seeds recorded from the 20 soil samples per plot (for more details see Maza-Villalobos et al., 2011b). Considering the fallow age of the plots in May 2004, this data were assigned to the Pasture, Early, Advanced, and OGF successional categories, while the Mid category had no data (Table S1).

\subsubsection{Seedling and resprout sampling}

Seedlings and resprouts were sampled in all study plots, following a regular spatial arrangement of 48 subplots of $1 \mathrm{~m}^{2}$ each ( $3 \mathrm{~m}$ apart) per plot. Individuals of 10-130 m height were recorded, tagged and identified at the end of the rainy season in October 2004. Data collected on this date corresponded to the Pasture successional category (Table S1). We did another sampling three years later (October 2007) in all plots. Considering the fallow age of the plots in that date, we assigned the collected data to the Early, Mid, Advanced and OGF successional categories (Table S1). Records from the 48 subplots were lumped to analyze the structural attributes and species composition of seedling and resprout stages per plot (for more details see Maza-Villalobos et al., 2013).

\subsubsection{Juvenile and adult sampling}

Juveniles were recorded, identified, and measured in DBH in half of each 0.1 ha plot, while adults were recorded, identified, and measured in DBH in the entire plot. Data for all these plants were obtained in October 2004, which were assigned to the Pasture successional category, and in October 2007 (for more details see Mora et al., 2015), which were assigned to the Early, Mid, Advanced, and OGF successional categories (Table S1).

\subsection{Data analysis}

\subsubsection{Structural community attributes}

Four structural attributes were evaluated per successional category and life stage: abundance (measured as plant density: seeds or plants per unit area), species density (number of species per unit area), species diversity of order 1 [Hill number $\mathrm{q}_{1}$, interpreted as the number of common species and calculated as the exponential of the Shannon diversity index (Chao et al., 2014)], and species dominance (species with highest relative abundance).

To test for differences in the trend of change of these response variables among successional categories and across life-stages, we used a two-step approach. First, we tested for differences among successional categories by fitting independent general linear models for each variable and each life stage using raw data. In this analysis, a Poisson error and a log-link function was set as all response variables were of count nature. Secondly, for each response variable, we assessed if differences among successional categories were dependent on life stage, i.e., by the life stage $\times$ successional category interaction. Because of the differences in sampling effort for different life stages, we standardized each structural variable into a $0-1$ range, taking as 1 the maximum value of the variable recorded across all plots. Then, we fitted linear mixed-effect (lme) models including the effects of successional category, life stage, and the life stage $\times$ successional category interaction. Site was included as a random factor to account for the non-independence of observations from the same site. The standardized response variables were logittransformed to conform the normality assumptions of the models (Warton and Hui, 2011). Model fitting was done using the "Imer" 
function in the lme4 package (Bates et al., 2015); significance of the terms was assessed using the "ANOVA" function in the car package (Fox and Weisberg, 2011). Post hoc Tukey tests were performed to evaluate differences among successional categories within each life stage using the lsmeans package (Lenth, 2016).

\subsubsection{Species dominance}

Changes in species dominance among life stages and successional categories were analyzed using rank-abundance curves (Magurran, 2004). We generated one single curve per successional category and life stage, by combining data from the three sites of the same successional category, to calculate species relative abundance. Then, we plotted species relative abundance (in log scale) vs. species rank (in a decreasing order of relative abundance) for each life stage and successional category, and fitted the data to geometric (semi-log) or Zipf (log-log) models (Wilson, 1991). The best-fitted models were those explaining the higher proportion of total variance $\left(\mathrm{R}^{2}\right)$. The two species with the highest relative abundance, in each life stage and successional category, were considered as the dominant species. Finally, we used ANCOVA to test for differences in evenness (slope of the rank-abundance curves) among life stages and successional categories. A stepper slope indicates lower evenness or higher dominance. In this analysis, log (relative abundance) was the dependent variable, species rank the regressor, and life stage and successional category were two factors with five levels each. Interactions between these independent variables were used to assess changes in evenness among life stages and successional categories.

\subsubsection{Species composition}

To assess changes in species dissimilarity among successional categories and life stages we used Non-metric Multidimensional Scaling (NMDS) and permutational MANOVA (PERMANOVA) analyses. First, Morisita-Horn similarity matrices (S) based on relative species abundances and corrected for unseen species were calculated both across successional categories within each life stage, and across life stages within each successional category, using the 'SimilarityMult' function of the 'SpadeR' library for R (Chao et al., 2016). Then, dissimilarities matrices were calculated as 1-S and subjected to NMDS ordination using the 'metaMDS' function of the 'vegan' library for R (Oksanen et al., 2019). Finally, to test for differences in species composition among successional categories within each life stage, or among life stages within each successional category, we ran PERMANOVA based on the dissimilarities matrices using the function 'adonis2' in the 'vegan' library (Oksanen et al., 2019). In all cases, we probed that the variance among groups was homogeneous, as required by PERMANOVA.

\subsubsection{Phylogenetic structure}

To address the possible mechanisms acting upon the assembly of shrub and tree communities, a phylogenetic approach was employed (Webb et al., 2002). We used a phylogenetic tree trimmed from the conserved phylogeny available in the BIEN package (Maitner et al., 2018). To test the prediction that phylogenetic clustering occurs early in succession and overdispersion later on in succession, we used the phylogenetic mean pairwise distance metric (MPD). This was done under the assumption that species conserve their niches and related ecological triats across space and time. The MPD metric measures the average distance between species across the phylogeny (Webb, 2000; Swenson, 2014; Tucker et al., 2017). MPD was calculated for each life stage, separately, combining species abundance data from the three plots per successional category. To test if the MPD values were different to those from a null model, we calculated the standardized effect size (SES.MPD; Swenson, 2014). We used the null model "Richness" (Miller et al., 2017), which shuffles species abundances randomly within a successional category while maintaining species richness and total abundance of that category. Negative SES.MPD values (significantly different from zero) indicate phylogenetic clustering, while positive values (significantly higher than zero) indicate phylogenetic overdispersion. Finally, we analyzed changes in clade composition among life stages and successional categories, assigning species to taxonomic orders and major clades following the phylogenetic tree in Soltis et al. (2018).

\section{Results}

\subsection{Structural community attributes}

Different trajectories of change in structural attributes across successional stages occurred for the different life stages (Fig. 1). The seed, seedling and adult stages showed lower values of plant density, species density, and species diversity in the three earlier successional categories and these increased in the Advanced and OGF categories, showing a Sshape of successional change. The juvenile stage showed a progressive increase from the earlier to later successional categories for these attributes. In contrast, the resprout stage showed a U-shape pattern for all structural attributes. Finally, species diversity did not change across successional categories in the seed and resprout stages.

A significant interaction between life stage and successional category, considering the standardized values (Fig. S3), was detected only for species diversity $\left(\mathrm{F}_{16,40}=3.31, \mathrm{P}=0.011\right)$. This occurred because while in the seed and resprout stages species diversity did not change among successional categories, in all the other life stages this attribute increased from earlier to later successional categories.

\subsection{Species dominance}

Dominance and evenness changed among life stages and across successional categories (Fig. 2) as indicated by the significant interaction among species rank $\times$ life stage $\times$ successional category $\left(\mathrm{F}_{16,612}=\right.$ $6.14, \mathrm{P}<0.0001)$. The highest dominance occurred in the seed or seedling stages in all successional categories (steeper slopes of rankabundance curves), while the higher evenness occurred in the juvenile stage in the Advanced successional category (least steep slope). Overall, geometric (exponential regression model) rank-abundance curves were more frequent in the seed, seedling and resprout stages for the majority of the successional categories (except the OGF), while Zipf (log-log, power regression model) curves were more frequent in the juvenile and adult stages, mainly in the OGF category.

Almost $60 \%$ of all dominant species across life stages and successional categories belonged to the Fabaceae family (Fig. 2). However, within each life stage, the identity of the dominant species was different among successional categories, except in the seedling stage for which Croton roxanae dominated in the two older successional categories and in the resprout stage for which Coccoloba liebmanii was dominant in the Mid and OGF categories (Fig. 2). Also, within successional categories, overall, we found that the identity of dominant species changed among life stages, although there were some exceptions to this pattern (Fig. 2).

\subsection{Species composition}

Dissimilarity in species composition among successional categories tended to increase from the younger to the older life stages, as shown by the NMDS and PERMANOVA analyses (Fig. 3a). The earlier life stages (i. e., seed, seedling, and resprout) showed the smallest dissimilarity among successional categories, while the juvenile and adult stages showed the largest one. Species composition was more similar among life stages at the earlier successional categories than it was at the later ones (Fig. 3b). In the Advanced and OGF categories the highest dissimilarity among life stages occurred, with the younger life stages being dissimilar to the oldest ones (Fig. 3b).

\subsection{Phylogenetic structure}

The mean phylogenetic distance among species (MPD) tended to 


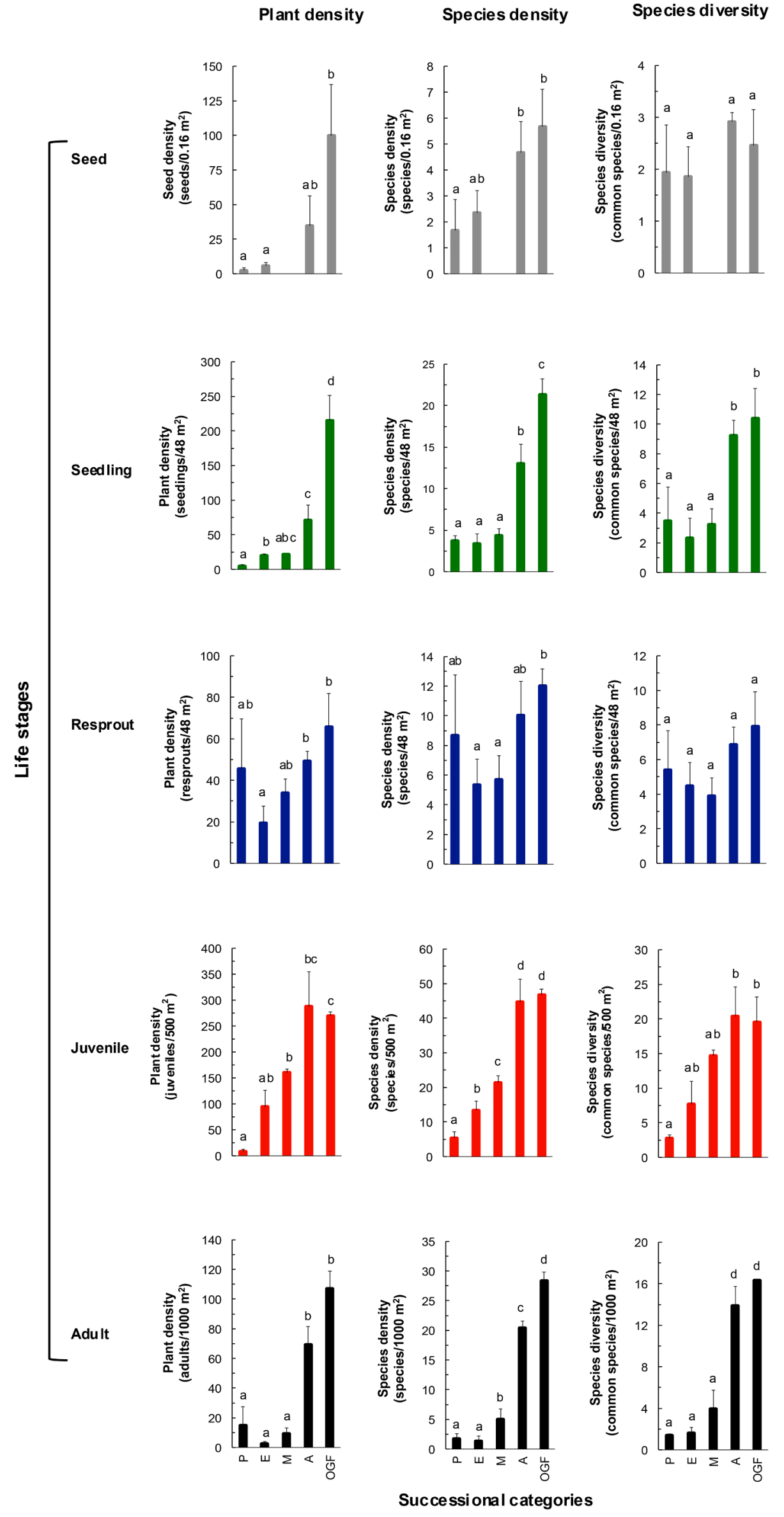


Fig. 1. Successional changes in plant density, species density, and species diversity (number of common species) among successional categories and life cycle stages of shrub and tree assemblages at Chamela, western Mexico. For each life-stage and community structure variable, letters indicate significant differences ( $\mathrm{P} \leq 0.05$ ) among successional categories according to general linear models and post-hoc Tukey tests. Successional categories: $\mathrm{P}=$ Pasture, $\mathrm{E}=$ Early, $\mathrm{M}=$ Mid, $\mathrm{A}=$ Advanced, OGF = Old-Growth Forest.

increase from Pasture to later successional categories in most life stages (Fig. 4a). The exception was the seed stage that showed maximum MPD in the Early successional category.

A change from clustered to random phylogenetic community structure was observed along succession for most life stages (Fig. 4b). For resprouts and juvenile stages, the phylogenetic community structure showed a clustered pattern in the Pasture category, flipping to random in the following successional categories. A similar pattern was found for adults, switching from clustered in the Pasture and Early categories to random in the following categories. In contrast, the seedling stage showed a clustered structure in most categories, except in the OGF category where it was random. The seed stage exhibited a random structure across all successional categories.

One clade (Eurosid I), in particular the Fabales order and the Fabaceae family were strongly dominant both in abundance and in number of species in the early successional category for all life-cycle stages (Fig. 5). In the latter successional categories such dominance decreased and the evenness in abundance and diversity increased among clades from different phylogenetic linages.

\section{Discussion}

\subsection{Successional patterns for different life-cycle stages}

What successional trajectories do assemblages of shrubs and trees follow along TDF succession? Are such trends similar comparable among all life-cycle stages?

While our results parallel the increase in plant density and species diversity along succession documented in other studies (Ruiz et al., 2005; Lebrija-Trejos et al., 2008; Bhaskar et al., 2014, Mora et al., 2015), we found noticeable variants for some life stages.

An S-shaped successional change was observed for plant density and species density at the seed and seedling stages. A very low density and species density of seeds in the soil and seedlings in recently abandoned fields represent a bottleneck for forest regeneration (Griscom and Ashton, 2011). Several ecological processes could produce such bottleneck, e.g., dispersal limitation, high seed predation, or a very low seedling emergence and survival (Rico-Gray and García-Franco, 1992; GarcíaOrth and Martínez-Ramos, 2008; Maza-Villalobos et al., 2013). Also, the slash-and-burn practices have been shown to produce a severe reduction in the density and diversity of the seed bank of shrubs and trees in recently abandoned pastures (Miller 1999). All of these factors can explain the poor seed bank and seedling density we recorded in the early successional categories (Fig. 1). As succession advances, the increase in forest complexity and in resources for animals (e.g., food items, perches, nesting sites) promotes the arrival of seeds being dispersed by seeddispersing frugivores (Chazdon et al., 2011; Almazán-Nuñez et al., 2015). Also, the increasing forest biomass and foliage cover reduce the harshness of environmental conditions (Lebrija-Trejos et al., 2011; Mora et al., 2018), which might favor seedling recruitment (Maza-Villalobos et al., 2013). In addition, an increasing number of maturing shrubs and trees during succession would enhance the abundance and richness of the local seed rain, and hence of seedlings, especially late in succession (Fig. 2).
In contrast, the U-shape successional change exhibited by resprouts (Fig. 1) suggests the operation of multiple processes. The high plant density and species density of resprouts in the Pasture category resulted from roots and stumps remaining after field abandonment. The capacity of resprouting is a common trait of TDF woody species and represents an adaptation to strong disturbances, such as severe droughts and physical and biotic damages (Bellingham and Sparrow, 2000; Poorter et al., 2010). Resprouts endure better than seedlings the harsh environmental conditions prevailing in recently abandoned fields (Miller and Kauffman, 1998). Large root systems and higher amounts of stored C reserves (in roots and stems) confer resprouts higher survivorship rates than seedlings, which have, on average, lower amounts of maternal reserves (Poorter et al., 2010; Maza-Villalobos et al., 2013). After an initial wave of resprouts early in succession, the density and diversity of resprouts decreased in the Early successional category, likely reflecting that the initial bank of resprouts had been exhausted. Later on, in the Advanced and OGF categories, the resprout stage increased both in plant density and species density (Fig. 1), likely because a proportion of the increasing number of shrubs and trees establishing during succession suffered damages and resprouted. Considering that in the earliest successional categories the density of plants and species of the resprout stage was higher than those of the seedling stage (Fig. 1), we infer that resprouts were relatively more important than seedlings as a source of regeneration at the beginning of succession. In contrast, in the latest successional categories, the seedling stage was denser in plants and species than resprouts. Therefore, we infer that seedlings (and hence seeds) increased in importance as a source of regeneration late in succession (Fig. 1).

The S-shaped successional change of plant density and species density observed in the adult stage has been reported in other TDFs (LebrijaTrejos et al., 2008; Chazdon et al., 2011; Williams-Linera et al., 2011). Such pattern likely resulted from a few remaining isolated trees in the recently abandoned pastures, as well as from the time needed for newly recruited trees and shrubs to grow into adult sizes $(\geq 2.5 \mathrm{~cm} \mathrm{DBH})$. Previous hypotheses suggested that a S-shaped successional change could be indicative of an early dominance of shrubs (which generally are smaller than trees), and their replacement by trees as successional progresses. However, trees were more abundant and richer in species than shrubs across all successional categories, which do not support such idea (Fig. S2). Instead, we think that the few isolated trees that people usually leave in their pastures, as a source of shade or food for cattle (OteroArnaiz et al., 1999; Mora et al., 2015), explain the low density and diversity of adult plants in the Pasture and Early categories. Adult plants increased in the Advanced successional category (12-15 years after field abandonment; Fig. 1), indicating that more than ten years are needed for the new colonizing shrubs and trees to attain large sizes $(\geq 2.5 \mathrm{~cm} \mathrm{DBH})$.

\subsection{Life stages, filtering and succession}

Do plants from different life stages cope with distinct ecological filters during succession? If so, such filtering processes can help us to better understand the old-field TDF succession?

Our results suggest that ecological filters differed among life-cycle stages during succession. Two evidences suggest that abiotic filters played an important role in assembling communities of trees and shrubs 


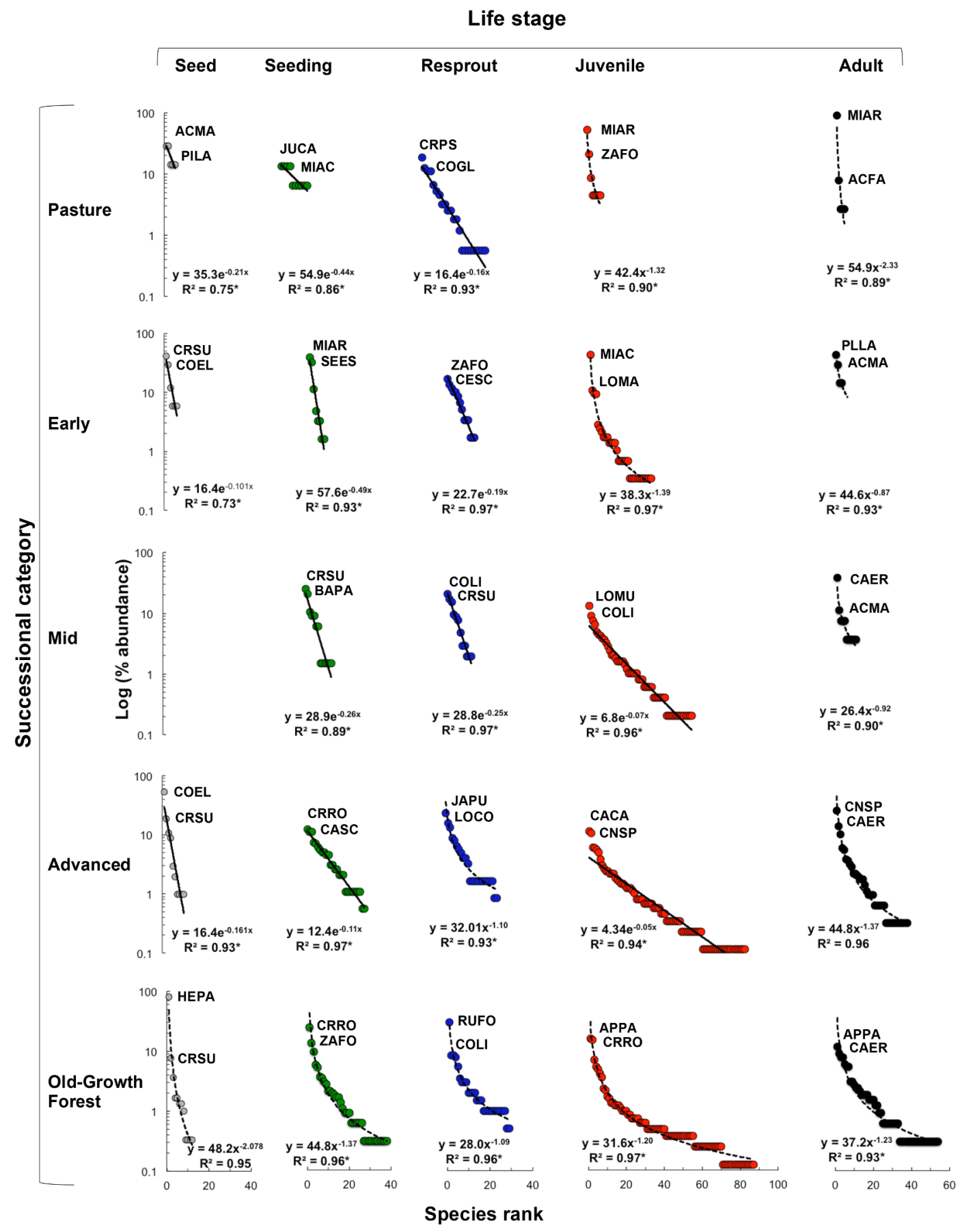

Fig. 2. Change in rank-abundance curves for different life-cycle stages during the old-field tropical dry forest succession at Chamela, western Mexico. Species names of the two dominant species for each life stage and successional category are: ACMA = Acacia macrantha, ACFA = Acacia farnesiana, APPA $=$ Apoplanesia paniculata, BAPA $=$ Bauhinia pauletia, CACA $=$ Caesalpinia caladenia, $\mathbf{C A E R}=$ Caesalpinia eriostachys, $\mathbf{C E S C}=$ Caesalpinia sclerocarpa, CNSP $=$ Cnidoscolus spinosus, COGL $=$ Cordia globulifera, $\mathrm{COEL}=$ Cordia eleagnoides, $\mathrm{COLI}=$ Coccoloba liebmanii, $\mathrm{CRPS}=$ Croton pseudoniveus, $\mathrm{CRRO}=$ Croton roxanae, $\mathrm{CRSU}=$ Croton suberosus, $\mathrm{HEPA}=$ Heliocarpus pallidus, JUCA $=$ Justicia candicans, JAPU $=$ Jacquinia pungens, LOCO $=$ Lonchocarpus constrictus, LOMA $=$ Lonchocarpus magallanensis, LOMU $=$ Lonchocarpus mutans, MIAC $=$ Mimosa acantholoba, MIAR $=$ Mimosa arenosa, PLLA $=$ Platymiscium lasiocarpum, RUFO $=$ Ruellia foetida, SEES $=$ Senna estipula, ZAFO $=$ Zapoteca formosa. Acronyms in bold correspond to species in the Fabaceae family. Curves best fitted to power regression models $\left(\mathrm{Y}=\mathrm{A}^{*} \mathrm{X}^{-\mathrm{B}}\right.$, discontinuous lines) correspond to Zift $(\log -\log )$ rank-abundance curves, while those best fitted to exponential regression ones $\left(\mathrm{Y}=\mathrm{A}^{*} \exp ^{-\mathrm{B}}\right.$, continuous lines) correspond to geometric curves.

early in succession, especially in the seedling stage. First, assuming species niche and trait conservatism, the strong clustered phylogenetic structure observed in most life stages in the earliest successional category is suggestive of abiotic filtering (Webb et al., 2002; Letcher, 2009). Second, while in the seed stage a random phylogenetic structure was found along the first 15 years of succession, a clustered structure was observed in the seedling stage (Fig. 4b). The seed stage comprised species from a wide range of clades, whereas the seedling stage comprised species mostly from the Fabales order (Fig. 5). As a result, species composition of the seed stage was different from that of the seedling stage in most successional categories (Fig. 3b). These results suggest that the harsh environmental conditions, prevailing during the early years of 

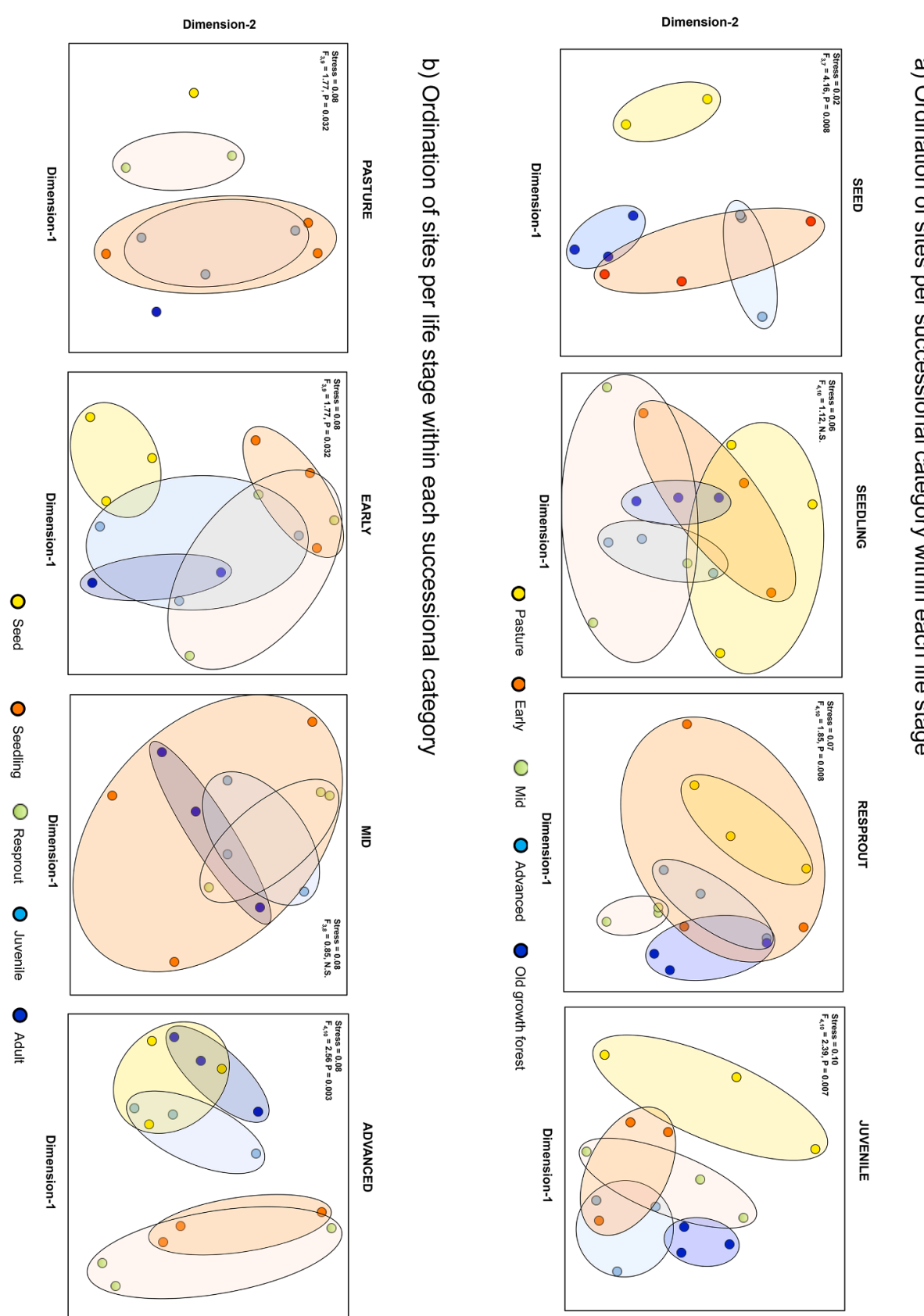

Fig. 3. NMDS ordination of sites based on species dissimilarity (Morisita-Horn index) among: (a) successional categories within a given life stage, and (b) among life-cycle stages within a given successional category. Data from the tropical dry forest of Chamela, western Mexico. In each panel, dots and ovals of same color correspond to same successional category or life stage. Ovals not overlapping are significantly different $(P \leq 0.05)$. Inset each panel, Values of NMDS stress and PERMANOVA statistics are shown.
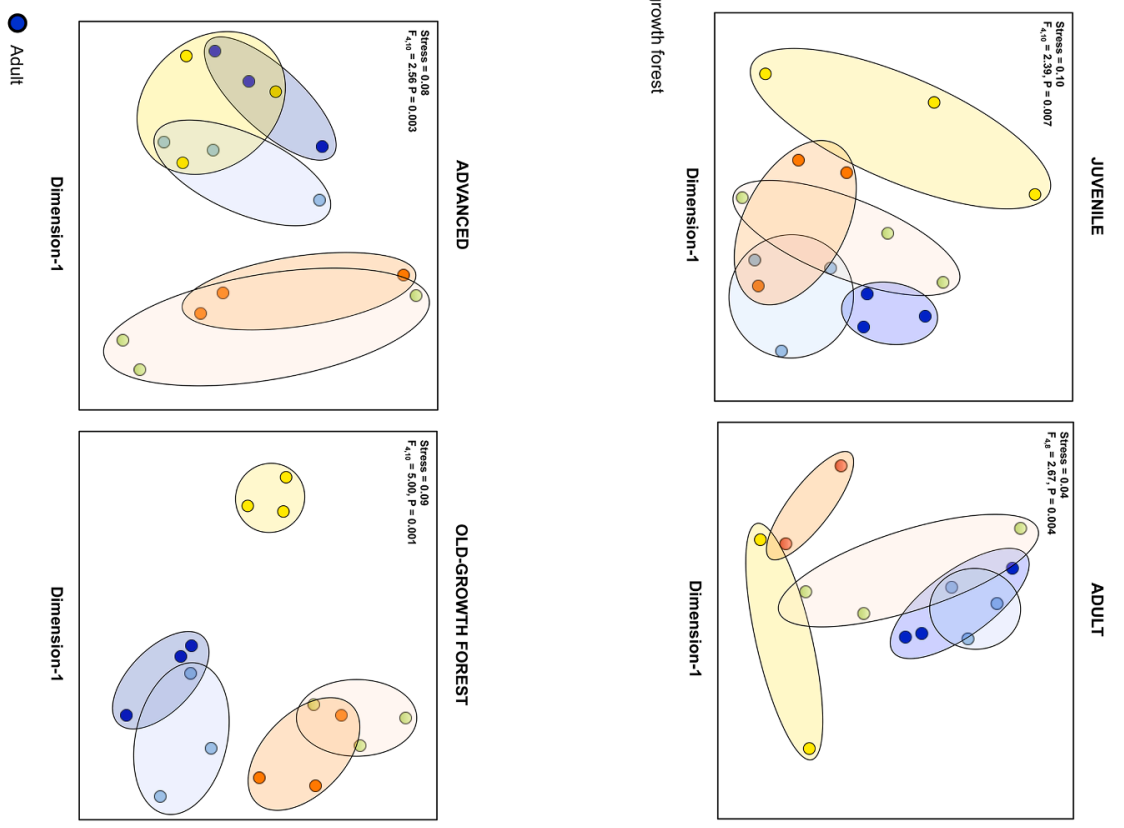

succession (Lebrija-Trejos et al. 2011; Pineda-García et al., 2013), sift species from the seed bank so that mostly species of Fabales get established as seedlings. Legumes species have been repeatedly identified as stress-tolerant and resilient to drought (Pineda-García et al., 2013; Gei et al., 2018, Maza-Villalobos et al., 2020). In fact, in Chamela, legume pioneer tree species have been found to show a higher foraging capacity for soil water than late successional species, by producing long root systems that grow deeply into the soil (Paz et al., 2015).

We also found three lines of evidence to support the idea that biotic filters increase along succession. First, in contrast to the seedling stage, the tendency for an overdispersed structure of the resprout stage in the successional categories other than the Pasture one suggests the 


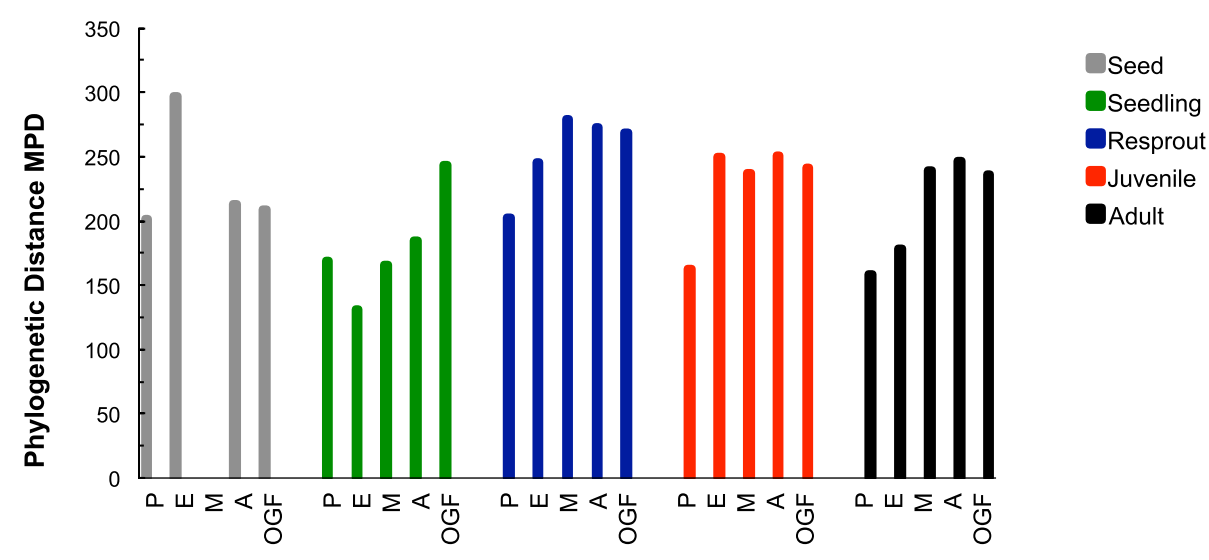

Fig. 4. Phylogenetic changes among successional categories at different life stages of shrubs and trees of the tropical dry forest of Chamela, western Mexico. a) Phylogenetic mean parwise distance (MPD), an indicator of community phylogenetic diversity. b) Standardized effect size of MPD; Negative values infer clustering, positive values indicate overdispersion; Red dots indicate cases where the observed phylogenic community structure was different from a random structure $(\mathrm{P}<0.05)$. Successional categories: $\mathrm{P}=$ Pasture, $\mathrm{E}=$ Early, $\mathrm{M}=\mathrm{Mid}, \mathrm{A}=$ Advanced, $\mathrm{OGF}$ = Old-Growth Forest. (For interpretation of the references to color in this figure legend, the reader is referred to the web version of this article.)

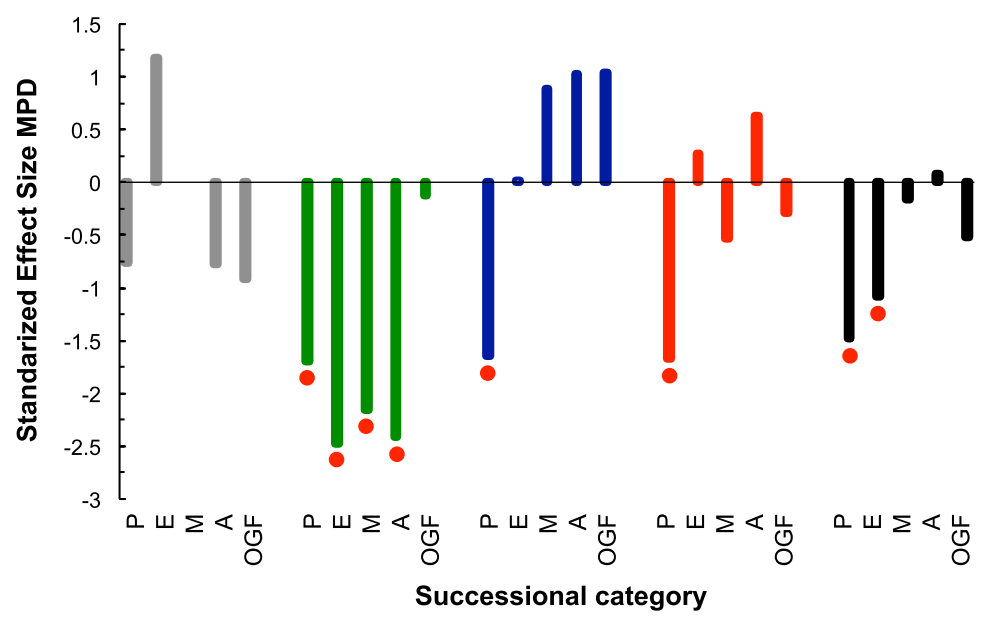

operation of biotic filters (Fig. 4). The resprout stage comprised species from several distantly related clades (Fig. 5), suggesting that assembly mechanisms other than, or in addition to, abiotic filtering influence the structure of resprout communities. Resprouting is a plant adaptation that evolved in different lineages of woody plant communities subjected to strong disturbances (Vesk and Westoby, 2004). Therefore, we infer that species belonging to several distant related clades get established during succession via resprouts, because resprouts withstand better than seedlings the long and severe dry season typical of TDF localities. Using our study system, other study has been shown that, although seedlings have $30 \%$ higher recruitment rate than resprouts, resprouts survive at rates twice as high as seedlings (Maza-Villalobos et al., 2013). Thus, while species from several orders other than Fabales were impeded to regenerate from seedlings, resprouts represented for them an important source for regeneration.

Second, from the Pasture to the OGF successional categories, within each life stage (especially in the adult stage), the rank-abundance curves changed from a geometric type to a Zipf one (Fig. 2). A geometric curve is commonly found for plant communities colonizing sequentially an open space, while a Zipf curve is interpreted as resulting from a process of niche partitioning among ecologically differentiated species (Magurran, 2004). Such change was paralleled by an increase in the diversity of taxonomic orders as succession advanced, which was observed in all life stages (Fig. 5). Third, MPD increased from the earliest to later successional categories in most life stages (Fig. 4a), which indicates that a larger number of distantly related species (purportedly ecologically different) become members of the community as succession advances.

Forth, during succession the phylogenetic community structure changed from clustered to random in most life stages. A random phylogenetic structure could result when abiotic and biotic filters operate in the community (Kembel and Hubbell, 2006; Mayfield and Levine, 2010; Ndiribe et al., 2013; Chai et al., 2016). A combination between abiotic filtering operating mostly in the transition of the seedling stage to further life stages, and biotic filtering becoming more important in the transition of the resprout stage to further life stages, could result in the random phylogenetic structure observed in the juvenile and adult stages (Fig. 4). In concordance with this idea, in the Advanced and OGF categories the higher species dissimilarity occurred between the regenerative stages (seed, seedling, resprout) and the juvenile and adult stages (Fig. 3b), which suggests that species-specific natural enemies (such as seed predators, herbivores, or pathogens) can impede self-regeneration of species dominating the site, favoring the regeneration of non-prey plant species (Janzen, 1970; Connell, 1971; Martínez-Ramos and Soto-Castro, 1993). This reasoning is in line with the expectation that biotic filters play an important role in the maintenance of species diversity late in succession.

\subsection{Implications for TDF management in human modified landscapes}

The study region in the Pacific coast of Mexico is representative of the human modified landscapes arising from the TDF conversion to agriculture in Mesoamerica (Quesada et al., 2009). A major socioecological challenge in such landscapes is to find ways to conserve TDF biodiversity, its functions, and services while producing the food demanded by an increasing human population, supporting the livelihoods of the local small holders, and addressing the differential burdens and benefits experienced by different stakeholders (Harvey et al., 2008; 


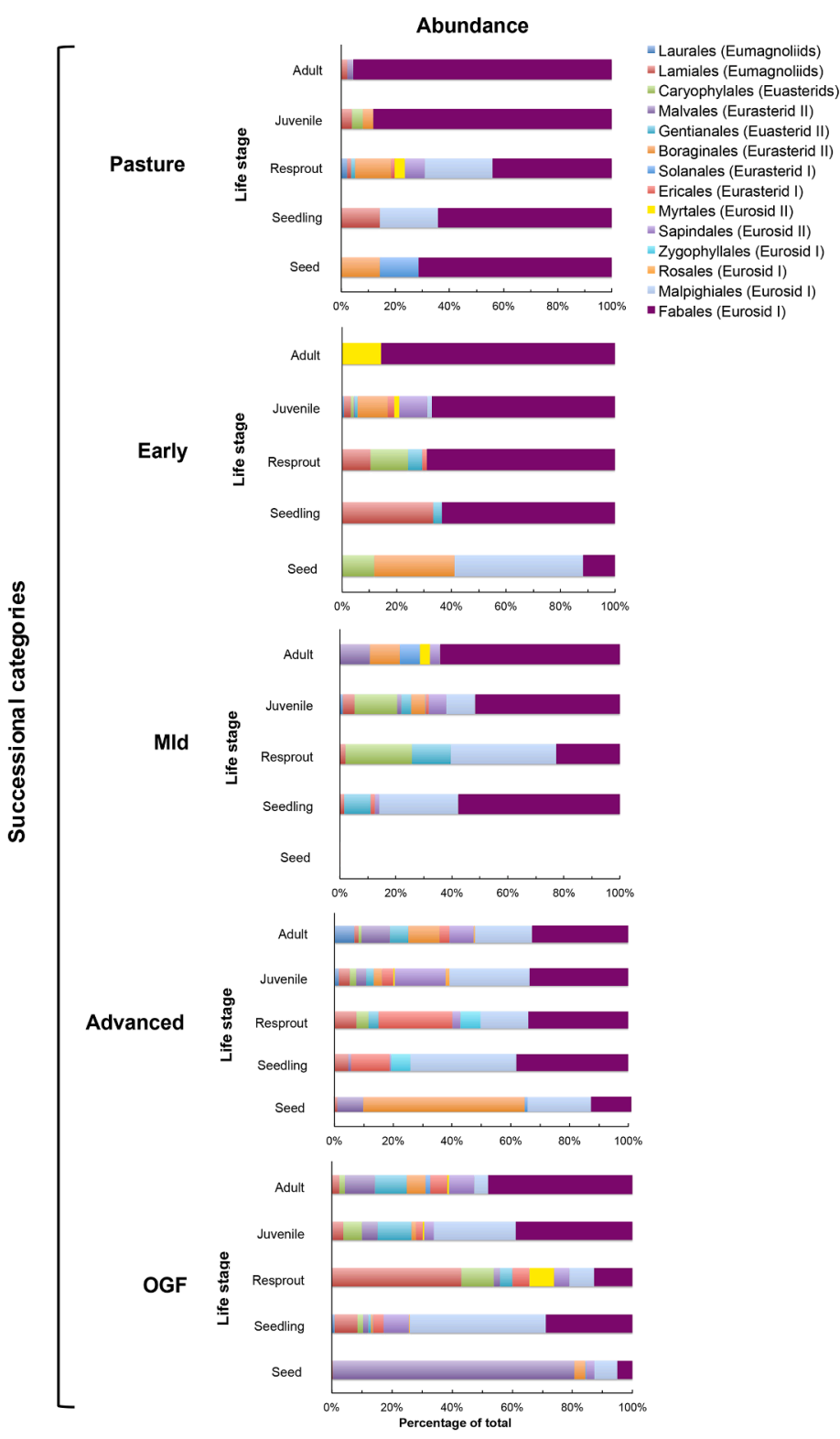

Chazdon et al., 2009; Gardner et al., 2009; Quesada et al., 2009; Mora et al., 2015; Lazos-Chavero et al., 2016). The results of the present study provide important insights to inform the management of TDF (whether aimed at biodiversity conservation, restoration, sustainable use of wood and other forest products, or landscape restoration), which can be summarized into the following principles.

- Landscape management. Seeds and seedlings were found at very low densities and species densities in recently abandoned pastures. To cope with this potential bottleneck for forest regeneration and succession, management at the landscape scale would ensure that enough forest in the matrix remains to function as a source of species (see more details in Pérez-Cárdenas et al., 2021). The high prevalence of wind-dispersed species in old-growth and secondary TDFs (Vieira and Scariot, 2006; Ceccon and Hernández, 2009; Hilje et al., 2015), which can disperse over long distances (Green and Johnson, 1995), enhances the important role of remaining old growth and old secondary forests in the landscape and thereby the strong function of the landscape matrix. Additionally, the relatively low numbers of animal-dispersed species in TDFs call for active protection of animal-
Number of species
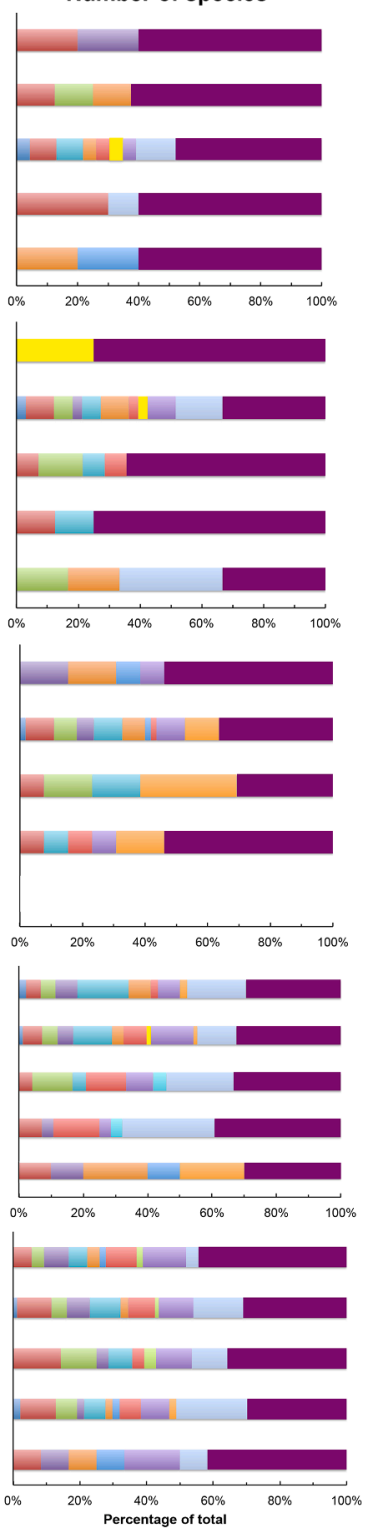

Fig. 5. Changes in clade composition for assemblages of shrub and tree species at different life stages during old-field tropical dry forest succession, in Chamela, western Mexico. Each color represents a taxonomic order; in parenthesis is indicated the clade where each order is located in the phylogenetic tree constructed for angiosperms by Soltis et al (2018). Panels in the left column indicate the relative abundance (\%) of each order in each life stage and successional category. Panels in the right column indicate percentage of species of each order recorded for in a given life stage and successional category. OGF corresponds to Old-Growth Forest category. Relative values are based on totals calculated from three plots per successional category. Note the dominance of Fabales (purple color) in most panels. (For interpretation of the references to color in this figure legend, the reader is referred to the web version of this article.) dispersed species in the landscape, and for maintaining and possibly upgrading forested corridors and stepping-stones in the landscape.

- Agricultural land-use regimes. At the field level, addressing the negative impacts of high-intensive agricultural land-use regimes on early regeneration is also relevant (Kennard et al., 2002; ZermeñoHernández et al., 2015; Chazdon and Guariguata, 2016; Lohbeck et al., 2020; but see Pérez-Cárdenas et al., 2021). For example, slashand-burn practices, which are essential for the maintenance of extensive cattle pastures (Trilleras et al., 2015; Sánchez-Romero et al., 2021) but have negative impacts on the seed bank and seedling stocks (Miller 1999), could be replaced to give rise to other land uses. Agricultural practices limiting fire (such as controlled burning, plowing after harvest, Rodríguez-Trejo, 2008; Rodríguez-Trejo et al., 2011), combined with more selective weeding leaving a wide gamma of useful species, could conserve the forest regeneration potential and, at the same time, provide a wide array forest products for people. The conversion of cattle pastures into silvopastoral or agroforestry systems, based on second-growth forests with high abundance of "useful" species, would be an option to reduce such impacts. Second-growth forests provide diverse and nutritious fodder sources for cattle, but also provide other provisioning and regulating 
ecosystem services of high relevance for local communities (Naime et al., 2020; Cortés-Calderón et al., 2021). For example, a study carried out in our chronosequence system found that $53 \%$ of 177 registered woody species have one or more real or potential uses as livestock fodder (e.g., Brosimum alicastrum), food for people (e.g., Spondias purpurea), medicine (e.g., Amphipterygium adstringens), timber (e.g., Tabebuia rosea), firewood (e.g., Acacia farnesiana), aromatic resin (e.g., Bursera excelsa), ornamental plants (e.g., Caesalpinia pulcherrima), materials for construction (e.g., Cordia alliodora), among others (Godínez-Contreras, 2011). Of course, the conversion of pastures to silvopastoral or agroforestry systems in TDF regions require agreements and management strategies within a complex interplay of societal, economical, political, and biophysical factors (Sánchez-Romero et al., 2021).

- Management practices to accelerate the gain of forest biomass and foliage cover along succession. This action is critical to reduce the harshness of environmental conditions (Lebrija-Trejos et al., 2011; Mora et al., 2018), and favor seedling recruitment and survival (Maza-Villalobos et al., 2013). The transplanting of seedlings of Fabaceae pioneer species should help to this purpose. Legumes were most prominent in the early stages of succession in our study region, having survived the harsh abiotic filters operating in recently abandoned fields. Such legume prominence has been shown to be a general pattern across young secondary dry forests in the Neotropics (Gei et al., 2018). Legume species have also been shown to resist severe management legacies, and play a key role as fodder for cattle (Romero-Duque et al., 2007; Mora et al., 2016; Sánchez-Romero et al., 2021). Actively accelerating the gain of forest biomass should increase the value of secondary forest for programs promoting forest restoration to capture and storage atmospheric carbon, such as REDD+ (Paquette et al., 2009; Naime et al., 2020).

- Management of resprouts, seedlings, and biotic filters. Resprouts were shown to be critical for the development of secondary forests. Therefore, enriching secondary forests by transplanting resprouts from a wide set of distantly phylogenetically related species could enhance the recovery of diverse secondary forests. Resprouts can be developed from cutting branch tips (Itoh et al., 2002), and cuttings in dry systems have been shown to work reasonably well, both in Mexico (Castellanos-Castro and Bonfil 2013) and elsewhere (Haile et al., 2011). Farmer-management of resprouts has also been practiced for the restoration of TDFs (Chazdon 2014; Weston et al., 2015; Reij and Garrity 2016; Lohbeck et al., 2020). Once a forest cover has been developed, seedlings of valuable (e.g., timber) species could be transplanted to enrich the diversity and value of the second-growth TDFs (Vieira and Scariot, 2006; Paquette et al., 2009). Additionally, attracting seed-dispersing frugivores (Quesada et al., 2009; Chazdon et al., 2011; Almazán-Nuñez et al., 2015), and the enrichment with species of interest to local inhabitants, should enhance the already rapid recovery of the secondary forests observed here, and provide motivation to the people to keep and promote enriched secondary forests (Mora et al., 2016; Lazos-Chavero et al., 2016).

By combining the above suggested management strategies, the recovery of diverse secondary forests would contribute both to the conservation of biodiversity and to sustain people's livelihoods (Mora et al., 2016; Lazos-Chavero et al., 2016). Active involvement and social participation of local inhabitants into forest restoration projects is crucial but needs improvement (Ceccon et al., 2020).

\section{Conclusions}

Differences in structural community attributes, species composition, and phylogenetic structure, among life stages and successional categories, support the inference that old-field succession of the TDF is driven by abiotic filters operating mostly on seedling species, and by an increasing role of biotic filters operating mostly on resprout species as succession advances. Abiotic filters, related to low water availability and the harsh microclimate conditions (high irradiance, temperature, and evaporation demands) prevailing at the beginning of the succession, select mostly for species of drought-tolerant legumes, while biotic filters (related to plant-plant, plant-animal and plat-microbe interactions), select for species from a wide range of families and orders as harsh conditions reduce later in succession. The role of the gradient of low to higher water availability as a driver of successional changes in TDFs contrast with the role of high to low light gradient driving succession in tropical wet forests (Lohbeck et al., 2015; Gei et al., 2018; Poorter et al., 2019). Therefore, drought tolerance, rather than light acquisition, becomes a critical strategy for colonization during the old-field TDF succession. Our study represents a first step to incorporate chronosequence and plant life stages to the ecological analysis of old-field TDF succession. However, future long-term studies combining phylogenetic, demographic, and functional trait perspectives (e.g., Norden et al., 2012; Muscarella et al., 2017; Martínez-Ramos et al., 2018) could strengthen the findings here reported. This study also provides knowledge useful for the management of second-growth TDFs in human modified landscapes, including the selection of propagules (seedlings, resprouts) of shrub and tree species to foster forest regeneration in abandoned fields, and to enrich secondary forest with species offering a wide array of forest products and other ecosystem services.

\section{CRediT authorship contribution statement}

Miguel Martínez-Ramos: Conceptualization, Funding acquisition, Project administration, Methodology, Investigation, Formal analysis, Writing - original draft, Writing - review \& editing. Felipe Barragán: Conceptualization, Methodology, Formal analysis, Writing - original draft. Francisco Mora: Conceptualization, Investigation, Methodology, Formal analysis, Writing - review \& editing. Susana Maza-Villalobos: Investigation, Methodology, Data curation, Writing - original draft. Luis F. Arreola-Villa: Methodology, Data curation. Radika Bhaskar: Conceptualization, Methodology, Writing - review \& editing. Frans Bongers: Conceptualization, Methodology, Writing - review \& editing. Celina Lemus-Herrera: Investigation, Data curation. Horacio Paz: Conceptualization, Methodology, Writing - review \& editing. Angelina Martínez-Yrizar: Conceptualization, Methodology, Writing - review \& editing. Bianca A. Santini: Conceptualization, Formal analysis, Writing - review \& editing. Patricia Balvanera: Conceptualization, Investigation, Funding acquisition, Project administration, Methodology, Writing - review \& editing.

\section{Declaration of Competing Interest}

The authors declare that they have no known competing financial interests or personal relationships that could have appeared to influence the work reported in this paper.

\section{Acknowledgments}

We thank all facilities provided by the Estación de Biología Chamela (Instituto de Biología, Universidad Nacional Autónoma de México) to carry out this research. Thanks to E. Cisneros, C. Lemus, M. Álvarez Añorve, L.D. Ávila Cabadilla, O. Sánchez for fieldwork assistance. We are grateful to Alfredo Pérez-Jiménez ( $\dagger$ ) and Emily Lott for helping us with taxonomic identification. Research was supported by SEMARNATCONACYT 2002-C01-0597, SEP-CONACYT 83441, SEPCONACYT CB2005-01-51043, SEP-CONACYT CB-2009-129740, SEPCONACYT 179045, SEP-CONACYT 255544, PAPIIT-UNAM IN211114 and PAPIITUNAM IN211417. F. Barragan thanks CONACYT for a postdoctoral fellowship (agreement 290754) mentored by PB. We widely appreciate the invitation by Patricia Balvanera and Horacio Paz to contribute to the FORECO Special Issue on Tropical Secondary Forests. 


\section{Appendix A. Supplementary material}

Supplementary data to this article can be found online at https://doi. org/10.1016/j.foreco.2020.118810.

\section{References}

Almazán-Nuñez, R.C., Arizmendi, M.C., Eguiarte, L.E., Corcuera, P., 2015. Distribution of the community of frugivorous birds along a successional gradient in a tropical dry forest in south-western Mexico. J. Trop. Ecol. 31, 57-68.

Arroyo-Rodríguez, V., Melo, F.P.L., Martínez-Ramos, M., Bongers, F., Chazdon, R.L., Meave, J.A., Norden, N., Santos, B.A., Leal, I.R., Tabarelli, M., 2017. Multiple successional pathways in human-modified tropical landscapes: new insights from forest succession, forest fragmentation and landscape ecology research. Biol. Rev. 92, 326-340.

Bazzaz, F.A., 1979. The physiological ecology of plant succession. Annu. Rev. Ecol. Syst. 10, 351-371.

Bates, D., Maechler, M., Bolker, B., Walker, S., 2015. lme4: Linear mixed-effects models using Eigen and S4. R package version 1.1-7. 2014. http://CRAN.R-project.org/ package $=$ lme 4 .

Bhaskar, R., Dawson, T.E., Balvanera, P., 2014. Community assembly and functional diversity along succession post-management. Funct. Ecol. 28, 1256-1265.

Bellingham, P.J., Sparrow, A.D., 2000. Resprouting as a life history strategy in woody plant communities. Oikos 89, 409-416.

Bullock, S.H., Solís-Magallanes, J.A., 1990. Phenology of canopy trees of a tropical deciduous forest in Mexico. Biotropica 22, 22-35.

Bullock, S.H., Mooney, H.A., Medina, E. (Eds.), 1995. Seasonally Dry Tropical Forests. Cambridge University Press.

Cadotte, M.W., Tucker, C.M., 2017. Should environmental filtering be abandoned? Trends Ecol. Evol. 32, 429-437.

Castellanos-Castro, C., Bonfil, C., 2013. Propagation of three Bursera species from cuttings. Botan. Sci. 91, 217-224.

Ceccon, E., Hernández, P., 2009. Seed rain dynamics following disturbance exclusion in a secondary tropical dry forest in Morelos, Mexico. Revista de Biología Tropicale 57, 257-269. http://www.scielo.sa.cr/scielo.php?script=sci arttext\&pid=S00 34-77442009000100023\&lng=en\&nrm=iso.

Ceccon, E., Méndez-Toribio, M., Martínez-Garza, C., 2020. Social participation in fores restoration projects: insights from a national assessment in Mexico. Hum. Ecol. https://doi.org/10.1007/s10745-020-00178-w.

Chai, Y., Yue, M., Liu, X., et al., 2016. Patterns of taxonomic, phylogenetic diversity during a long-term succession of forest on the Loess Plateau, China: insights into assembly process. Sci. Rep. 6, 27087. https://doi.org/10.1038/srep27087.

Chao, A., Ma, K. H., Hsieh, T. C., Chiu, C-H., 2016. SpadeR: Species-Richness Prediction and Diversity Estimation with R. R package version 0.1.1. https://CRAN.R-project. org $/$ package $=$ SpadeR

Chazdon, R.L., 2014. Second-Growth: The Promise of Tropical Forest Regeneration in an Age of Deforestation. The University of Chicago Press, Chicago, USA.

Chazdon, R.L., Guariguata, M.R., 2016. Natural regeneration as a tool for large-scale forest restoration in the tropics: prospects and challenges. Biotropica 48, 716-730.

Chazdon, R.L., Harvey, C.A., Komar, O., Griffith, D.M., Ferguson, B.G., MartínezRamos, M., Morales, H., Nigh, R., Soto-Pinto, L., van Breugel, M., Philpott, S.M., 2009. Beyond reserves: A research agenda for conserving biodiversity in humanmodified tropical landscapes. Biotropica 41, 142-153.

Chazdon, R.L., Harvey, C., Martínez-Ramos, M., Balvanera, P., Schondube, J.S.K., AvilaCabadilla, L.D., Flores-Hidalgo, M., 2011. Seasonally dry tropical forest biodiversity and conservation value in agricultural landscapes of Mesoamerica. In: Dirzo, R., Young, H.S., Mooney, H.A., Ceballos, G. (Eds.), Seasonally Tropical Dry Forests: Ecology and Conservation. Island Press, USA, pp. 195-219.

Chao, A., Gotelli, N.J., Hsieh, T.C., Sander, E.L., Colwell, R.K., Ellison, A.M., 2014 Rarefaction and extrapolation with Hill numbers. Ecol. Monogr. 84, 45-67.

Connell, J. H., 1971. On the role of natural enemies in preventing competitive exclusion in some marine animals and in rain forest trees. In: den Boer, P.J., Gradwell, G.R. (Eds.), Proceedings of the Advanced Study Institute on Dynamics of Numbers in Populations, Oosterbeek, 1970, pp. 298-312. Centre for Agricultural Publishing and Documentation, Wageningen.

Connell, J., Slatyer, R., 1977. Mechanisms of succession in natural communities and their role in community stability and organization. Am. Nat. 111, 1119-1144.

Cortés-Calderón, S., Mora, F., Arreola-Villa, F., Balvanera, P., 2021. Ecosystem services supply and interactions along secondary tropical dry forests succession. For. Ecol. Manage. (in press).

Cowles, H.C., 1911. The causes of vegetation cycles. Bot. Gaz. 51, 161-183.

Dexter, K.G., Pennington, R.T., Oliveira-Filho, A.T., Bueno, M.L., Silva de Miranda, P.L., Neves, D.M., 2018. Inserting tropical dry forests into the discussion on biome transitions in the tropics. Front. Ecol. Evol. 6, 104. https://doi.org/10.3389/ fevo.2018.00104.

Durán, E., Balvanera, P., Lott, E., Segura, G., Pérez-Jiménez, A., Islas, A., Franco, M., 2002. Estructura, composición y dinámica de la vegetación. In: Noguera, F.A. Vega, J.H., García, A.N., Quesada, M. (Eds.), Historia Natural de Chamela. UNAM, México, pp. 443-472

Finegan, B., 1984. Forest succession. Nature 312, 109-114.

Flores-Casas, R., Ortega-Huerta, M.A., 2019. Modelling land cover changes in the tropical dry forest surrounding the Chamela-Cuixmala biosphere reserve, Mexico. Int. J. Remote Sens. 40, 6948-6974.
Fox, J., Weisberg, S., 2011. Multivariate Linear Models in R. Sage Publications, Thousand Oaks, CA.

Fremout, T., Thomas, E., Gaisberger, H., et al., 2020. Mapping tree species vulnerability to multiple threats as a guide to restoration and conservation of tropical dry forests. Glob. Change Biol. 26, 3552-3568.

García-Orth, G., Martínez-Ramos, M., 2008. Seed dynamics of early and late successional tree species in tropical abandoned pastures: seed burial as a way of evading predation. Restor. Ecol. 16, 435-443.

Gardner, T.A., Barlow, J., Chazdon, R.L., Ewers, R.M., Harvey, C.A., Peres, C.A., Sodhi, N.S., 2009. Prospects for tropical forest biodiversity in a human modified world. Ecol. Lett. 12, 561-582.

Gei, M., Rozendaal, D.M.A., Poorter, L., et al., 2018. Legume abundance along successional and rainfall gradients in Neotropical forests. Nat. Ecol. Evol. 2, 1104.

Godínez-Contreras, M., 2011. Plantas útiles y potencialmente útiles del bosque tropical seco presentes en Chamela, Jalisco, México. MSc Thesis. Posgrado en Ciencias Biológicas, Universidad Nacional Autónoma de México.

Götzenberger, L., de Bello, F., Bråthen, K.A., Davison, J., Dubuis, A., Guisan, A., Lepš, J., Lindborg, R., Moora, M., Partial, M., Pellissier, L., Pottier, J., Vittoz, P., Zobel, K., Zobel, M., 2012. Ecological assembly rules in plant communities-approaches, patterns and prospects. Biol. Rev. 87, 111-127.

Griscom, H.P., Ashton, M.S., 2011. Restoration of dry tropical forests in Central America: A review of pattern and process. For. Ecol. Manage. 261, 1564-1579.

Grombone-Guaratini, M.T., Rodrigues, R.R., 2002. Seed bank and seed rain in a seasonal semi-deciduous forest in south-eastern Brazil. J. Trop. Ecol. 18, 759-774.

Green, D.E., Johnson, E.A., 1995. Long-distance wind dispersal of tree seeds. Can. J. Bot. 73, 1043-1055.

Harvey, C.A., Komar, O., Chazdon, R.L., Ferguson, B.G., Finegan, B., Griffith, D.M., Martínez-Ramos, M., Morales, H., Nigh, R., Soto-Pinto, L., van Breugel, M., Wishnie, M., 2008. Integrating agricultural landscapes with biodiversity conservation in the Mesoamerican hotspot. Conserv. Biol. 22, 8-15.

Hilje, B., Calvo-Alvarado, J., Jimenez-Rodriguez, C., Sánchez-Azofeifa, G.A., 2015. Tree species composition, breeding systems, and pollination and dispersal syndromes in three forest successional stages in a tropical dry forest in Mesoamerica Tropical Conservation. Science 8, 76-94.

Haile, G., Gebrehiwot, K., Lemenih, M., Bongers, F., 2011. Time of collection and cutting sizes affect vegetative propagation of Boswellia papyrifera (Del.) Hochst through leafless branch cuttings. J. Arid Environ. 75, 873-877.

Hu, Y.H., Lan, G.Y., Sha, L.Q., Cao, M., Tang, Y., Li, Y.D., et al., 2012. Strong neutral spatial effects shape tree species distributions across life stages at multiple scales. PLoS ONE 7, e38247. https://doi.org/10.1371/journal.pone.0038247.

Hubbell, S., 2011. The Unified Neutral Theory of Biodiversity and Biogeography, first ed. Princeton University Press, Princeton, USA.

Itoh, A., Yamakura, T., Kanzaki, M., Ohkubo, T., Palmiotto, P.A., LaFrankie, J.V., Kendawang, J.J., Lee, H.S., 2002. Rooting ability of cuttings relates to phylogeny, habitat preference and growth characteristics of tropical rainforest trees. For. Ecol. Manage. 168, 275-287.

Jakovac, C., Peña-Claros, M., Kuyper, Th.W., Bongers, F., 2015. Loss of secondary-forest resilience by land use intensification in the Amazon. J. Ecol. 103, 67-77.

Janzen, D.H., 1970. Herbivores and the Number of Tree Species in Tropical Forests. Am. Nat. 104, 501-528.

Kembel, S.W., Hubbell, S.P., 2006. The phylogenetic structure of a neotropical forest tree community. Ecology 87, S86-S99.

Kennard, D.K., Gould, K., Putz, F.E., Fredericksen, T.S., Morales, F., 2002. Effect of disturbance intensity on regeneration mechanisms in a tropical dry forest. For. Ecol, Manage. 162, 197-208.

Kraft, N.J.B., Ackerly, D.D., 2010. Functional trait and phylogenetic tests of community assembly across spatial scales in an Amazonian forest. Ecol. Monogr. 80, 401-422.

Lai, J., Mi, X., Ren, H., Ma, K., 2009. Species -habitat associations change in a subtropical forest of China. J. Veg. Sci. 20, 415-423.

Lazos-Chavero, E., Zinda, J., Bennett-Curry, A., Balvanera, P., Bloomfield, G., Lindell, C., Negra, C., 2016. Stakeholders and tropical reforestation: challenges, trade-offs, and strategies in dynamic environments. Biotropica 48, 900-914.

Lebrija-Trejos, E., Bongers, F., Pérez-García, E., Meave, J., 2008. Successional change and resilience of a very dry tropical deciduous forest following shifting agriculture. Biotropica 40, 431-442.

Lebrija-Trejos, E., Meave, J.A., Poorter, L., Pérez-García, E.A., Bongers, F., 2010a. Pathways, mechanisms and predictability of vegetation change during tropical dry forest succession. Perspect. Plant Ecol. Evol. Syst. 12, 267-275.

Lebrija-Trejos, E., Pérez-García, E., Meave, M., Bongers, F., Poorter, L., 2010 b. Functional traits and environmental filtering drive community assembly in a speciesrich tropical system. Ecology 91, 386-398.

Lebrija-Trejos, E., Pérez-García, E.A., Meave, J.A., Poorter, L., Bongers, F., 2011 Environmental changes during secondary succession in a tropical dry forest in Mexico. J. Trop. Ecol. 27, 477-489.

Lenth, R.V., 2016. Least-squares Means: The R Package lsmeans. 69, p. 33.

Letcher, S.G., 2009. Phylogenetic structure of angiosperm communities during tropical forest succession. Proc. R. Soc. B 277, 97-104.

Letcher, S.G., Chazdon, R.L., Andrade, A.C.S., Bongers, F., van Breugel, M., Finegan, B., Laurance, S.G., Mesquita, R.C.G., Martínez-Ramos, M., Bruce Williamson, G., 2012. Phylogenetic community structure during succession: Evidence from three Neotropical forest sites. Perspect. Plant Ecol. Evol. Syst. 14, 79-87.

Li, S., Cadotte, S.J., Meiners, Z., Hua, L., Shu, J.W., 2015. Species colonisation, not competitive exclusion, drives community overdispersion over long-term succession. Ecol. Lett. 18, 964-973.

Lohbeck, M., Lebrija-Trejo, E., Martínez-Ramos, M., Meave, J.A., Poorter, L., Bongers, F., 2015. Functional trait strategies of trees in dry and wet tropical forests are similar 
but differ in their consequences for succession. PLoS ONE 10 (4), e0123741. https:// doi.org/10.1371/journal.pone.0123741.

Lohbeck, M., Albers, P., Boels, L.E., et al., 2020. Drivers of farmer-managed natural regeneration in the Sahel. Lessons for restoration. Sci. Rep. 10, 15038. https://doi. org/10.1038/s41598-020-70746-Z.

Maass, M., Ahedo-Hernández, R., Araiza, S., Verduzco, A., Martínez-Yrízar, A. Jaramillo, V.J., Parker, G., Pascual, F., García-Méndez, G., Sarukhán, J., 2018. Long term (33 years) rainfall and runoff dynamics in a tropical dry forest ecosystem in western Mexico: management implications under extreme hydrometeorological events. For. Ecol. Manage. 426, 7-17.

Maitner, B.S., Boyle, B., Casler, N., et al., 2018. The BIEN R package: A tool to access the Botanical Information and Ecology Network (BIEN) Database. Methods Ecol. Evol. 9 , 373-379.

Magurran, A., 2004. Measuring Biological Diversity. Blackwell Publishing, Malden, USA.

Martins, A.M., Engel, V.L., 2007. Soil seed banks in tropical forest fragments with different disturbance histories in southeastern Brazil. Ecol. Eng. 31, 165-174.

Martínez-Ramos, M., Soto-Castro, A., 1993. Seed rain and advanced regeneration in a tropical rain forest. Vegetatio 108, 299-318.

Martínez-Ramos, M., Balvanera, P., Arreola, L.F., Mora, F., Maass, M., MazaVillalobos, S., 2018. Effects of long-term inter-annual rainfall variation on the dynamics of regenerative communities during the old-field succession of a Neotropical dry forest. For. Ecol. Manage. 426, 91-100.

Mayfield, M.M., Levine, J.M., 2010. Opposing effects of competitive exclusion on the phylogenetic structure of communities. Ecol. Lett. 13, 1085-1093.

Maza-Villalobos, S., Balvanera, P., Martínez-Ramos, M., 2011a. Early regeneration of tropical dry forest from abandoned pastures: contrasting chronosequence and dynamic approaches. Biotropica 43, 666-675.

Maza-Villalobos, S., Lemus-Herrera, C., Martínez-Ramos, M., 2011b. Successional trends in soil seed banks of abandoned pastures of a Neotropical dry region. J. Trop. Ecol. 27, 35-49.

Maza-Villalobos, S., Poorter, L., Martínez-Ramos, M., 2013. Effects of ENSO and temporal rainfall variation on the dynamics of successional communities in old-field succession of a tropical dry forest. PLoS ONE e82040. https://doi.org/10.1371/ journal.pone.0082040.

Maza-Villalobos, S., Ackerly, D., Oyama, O., Martínez-Ramos, M., 2020. Phylogenetic changes during secondary succession of a Neotropical dry forest: assembling processes and ENSO effects. Perspect. Plant Ecol. Evol. Syst. 43, 125513. https://doi. org/10.1016/j.ppees.2020.125513.

Miller, P.M., 1999. Effects of deforestation on seed banks in a tropical deciduous forest of western Mexico. J. Trop. Ecol. 15, 179-188.

Miller, P.M., Kauffman, J.B., 1998. Seedling and sprout response to slash-and-burn agriculture in a tropical deciduous forest. Biotropica 30, 538-546.

Miller, E.T., Farine, D.R., Trisos, C.H., 2017. Phylogenetic community structure metrics and null models: a review with new methods and software. Ecography 40, 461-477.

Mora, F., Martínez-Ramos, M., Ibarra-Manríquez, G., Pérez-Jiménez, A., TrillerasMotha, J., Balvanera, P., 2015. Testing chronosequences through dynamic approaches: time and site effects on tropical dry forest old-field succession. Biotropica 47, 38-48.

Mora, F., Balvanera, P., García-Frapolli, E., Castillo, A., Trilleras, J.M., CohenSalgado, D., Salmerón, O., 2016. Trade-offs between ecosystem services and alternative pathways toward sustainability in a tropical dry forest region. Ecol. Soc. 21, 45. https://doi.org/10.5751/ES-08691-210445.

Mora, F., Jaramillo, V.J., Bhaskar, R., Gavito, M., Siddique, I., Byrnes, J.E.K., Balvanera, P., 2018. Carbon accumulation in Neotropical dry secondary forests: the roles of forest age and tree dominance and diversity. Ecosystems 21, 536-550.

Muscarella, R., Lohbeck, M., Martínez-Ramos, M., Poorter, L., Rodríguez-Velázquez, J., van Breugel, M., Bongers, F., 2017. Demographic drivers of functional composition dynamics. Ecology 98, 2743-2750.

Naime, J., Mora, F., Mauricio Sánchez-Martínez, M., Arreola, F., Patricia Balvanera, P., 2020. Economic valuation of ecosystem services from secondary tropical forests: trade-offs and implications for policy making. For. Ecol. Manage. 473, 118294. https://doi.org/10.1016/j.foreco.2020.118294.

Ndiribe, C., Salamin, N., Guisan, A., 2013. Understanding the concepts of community phylogenetics. Evol. Ecol. Res. 15, 853-868.

Norden, N., Chazdon, R.L., Chao, A., Jiang, Y.H., Vílchez-Alvarado, B., 2009. Resilience of tropical rain forests: tree community reassembly in secondary forests. Ecol. Lett. 12, 385-394.

Norden, N., Letcher, S.G., Boukili, V., Swenson, N.G., Chazdon, R., 2012. Demographic drivers of successional changes in phylogenetic structure across life-history stages in plant communities. Ecology 93, S70-S82.

Otero-Arnaiz, A., Castillo, S., Meave, J., Ibarra-Manríquez, G., 1999. Isolated pasture trees and the vegetation under their canopies in the Chiapas Coastal Plain, Mexico. Biotropica 31, 243-254.

Oksanen, J., Blanchet, F.G., Friendly, M., Kindt, R., Legendre, P., McGlinn, D., Minchin, P.R., O'Hara, R. B., Simpson, G.L., Solymos, P., Stevens, M.H.H., Szoecs, E., Wagner, H., 2019. Vegan: Community Ecology Package. R package version 2.5-6. https $/ /$ CRAN.R-project.org/package = vegan

Paquette, A., et al., 2009. Enrichment planting in secondary forests: a promising clean development mechanism to increase terrestrial carbon sinks. Ecol. Soc. 14 (1). http://www.ecologyandsociety.org/vol14/iss1/art31/.

Paz, H., Pineda-García, F., Pinzón-Pérez, L.F., 2015. Root depth and morphology in response to soil drought: comparing ecological groups along the secondary succession in a tropical dry forest. Oecologia 179, 551-561.

Pérez-Cárdenas, N., Mora, F., Arreola-Villa, F., Arroyo-Rodríguez, V., Balvanera, P., Flores-Casas, A.R., Navarrete, A., Ortega-Huerta, M.A., 2021. Effects of landscape composition and land use intensity on secondary succession in a tropical dry forest. For. Ecol. Manage. (in preparation).

Pineda-García, F., Paz, H., Meinzer, F.C., 2013. Drought resistance in early and late secondary successional species from a tropical dry forest: the interplay between xylem resistance to embolism, sapwood water storage and leaf shedding. Plant Cell Environ. 36, 405-418.

Pickett, S.T.A., Collins, S.L., Armesto, J., 1987. A hierarchical consideration of causes and mechanisms of succession. Vegetatio 69, 109-114.

Poorter, L., Kitajima, K., Mercado, P., Chubiña, J., Melgar, I., Prins, H.H.T., 2010. Resprouting as a persistence strategy of tropical forest trees: relations with carbohydrate storage and shade tolerance. Ecology 91, 2613-2627.

Poorter, L., Rozendaal, D.M.A., Bongers, F., et al., 2019. Wet and dry tropical forests show opposite successional pathways in wood density but converge over time. Nat. Ecol. Evol. 3, 928-934. https://doi.org/10.1038/s41559-019-0882-6.

Powers, J.S., Feng, X., Sánchez-Azofeifa, A., Medvigy, D., 2018. Focus on tropical dry forest ecosystems and ecosystem services in the face of global change. Environ. Res. Lett. 13, 090201. https://doi.org/10.1088/1748-9326/aadeec.

Quesada, M., Sánchez-Azofeifa, A.G., Alvarez-Añorve, M., Stoner, K.E., AvilaCabadilla, L., Calvo-Alvarado, J., Castillo, A., Espírito-Santo, M.M., Fagundes, M., Fernandes, G.W., Gamon, J., Lopezaraiza-Mikel, M., Lawrence, D., CerdeiraMorellato, L.P., Powers, J.S., Neves, F.S., Rosas-Guerrero, V., Sayago, R., Sanchez Montoya, G., 2009. Succession and management of tropical dry forests in the Americas: review and new perspectives. For. Ecol. Manage. 258, 1014-1024.

Rico-Gray, V., García-Franco, J.G., 1992. Vegetation and soil seed bank of successional stages in tropical lowland deciduous forest. J. Veg. Sci. 3, 617-624.

Reij, C., Garrity, D., 2016. Scaling up farmer-managed natural regeneration in Africa to restore degraded landscapes. Biotropica 48, 834-843.

Rodríguez-Trejo, D.A., 2008. Fire regimes, fire ecology, and fire management in Mexico. Ambio 37, 548-556.

Rodríguez-Trejo, D.A., Martínez-Hernández, P.A., Ortiz-Contla, H., et al., 2011. The present status of fire ecology, traditional use of fire, and fire management in Mexico and Central America. Fire Ecol. 7, 40-56.

Romero-Duque, L.P., Jaramillo, V.J., Pérez-Jiménez, A., 2007. Structure and diversity of secondary tropical dry forests in Mexico, differing in their prior land use history. For. Ecol. Manage. 253, 38-47.

Ruiz, J., Fandiño, M., Chazdon, R.L., 2005. Vegetation structure, composition, and species richness across a 56-year chronosequence of dry tropical forest on Providencia Island, Colombia. Biotropica 37, 520-530.

Sánchez-Azofeifa, G.A., Quesada, M., Cuevas-Reyes, P., Castillo, A., SánchezMontoya, G., 2009. Land cover and conservation in the area of influence of the Chamela-Cuixmala Biosphere Reserve, Mexico. For. Ecol. Manage. 258, 907-912.

Sánchez-Romero, R., Balvanera, P., Castillo, C., Mora, F., García-Barrios, L.E., GonzálezEsquivel, C.E., 2021. Management strategies, silvopastoral practices and socioecological drivers in traditional livestock systems in tropical dry forests: an integrated analysis. For. Ecol. Manage. 479, 118506. https://doi.org/10.1016/j. foreco.2020.118506.

Soltis, D.E., Soltis, P.S., Endress, P.K., Chase, M.W., 2018. Phylogeny and Evolution of the Angiosperms: Revised and Updated Edition. Sinauer, Sunderland, Massachusetts, USA.

Stegen, J.C., Lin, X., Konopka, A.E., Fredrickson, J.K., 2012. Stochastic and deterministic assembly processes in subsurface microbial communities. ISMEJ 6, 1653-1664.

Swenson, N.G., 2014. Functional and Phylogenetic Ecology in R. Springer, New York.

Swenson, N.G., Stegen, J.C., Davies, S.J., Erickson, D.L., Forero-Montaña, J., Hurlbert, A. H., Kress, W.J., Thompson, J., Uriarte, M., Wright, S.J., Zimmerman, J.K., 2012. Temporal turnover in the composition of tropical tree communities: functional determinism and phylogenetic stochasticity. Ecology 93, 490-499.

Trilleras, J.M., Jaramillo, V.J., Vega, E.V., Balvanera, P., 2015. Effects of livestock management on the supply of ecosystem services in pastures in a tropical dry region of western Mexico. Agric. Ecosyst. Environ. 211, 133-144.

Tucker, C.M., Cadotte, M.W., Carvalho, S.B., Davies, T.J., Ferrier, S., Fritz, S.A., Grenyer, R., Helmus, M.R., Jin, L.S., Mooers, A.O., Pavoine, S., Purschke, O., Redding, D.W., Rosauer, D.F., Winter, M., Mazel, F., 2017. A guide to phylogenetic metrics for conservation, community ecology and macroecology. Biol. Rev. 92, 698-715.

Vesk, P.A., Westoby, M., 2004. Sprouting ability across diverse disturbances and vegetation types worldwide. J. Ecol. 92, 310-320.

Vieira, D.L.M., Scariot, A., 2006. Principles of natural regeneration of tropical dry forests for restoration. Restor. Ecol. 14, 11-20.

Warton, D.I., Hui, F.K.C., 2011. The arcsine is asinine: the analysis of proportions in ecology. Ecology 92, 3-10.

Webb, C.O., 2000. Exploring the phylogenetic structure of ecological communities: an example for rain forest trees. Am. Nat. 156, 145-155.

Webb, C.O., Ackerly, D.D., McPeek, M.A., Donoghue, M.J., 2002. Phylogenies and community ecology. Annu. Rev. Ecol. Syst. 33, 475-505.

Weston, P., Hong, R., Kabore, C., Kull, C.A., 2015. Farmer-managed natural regeneration enhances rural livelihoods in dryland West Africa. Environ. Manage. 55, 1402-1417.

Whitfeld, T.J.S., Kress, W.J., Erickson, D.L., Weiblen, G.D., 2012. Change in community phylogenetic structure during tropical forest succession: evidence from New Guinea. Ecography 35, 821-830.

Wilson, J.B., 1991. Methods for fitting dominance/diversity curves. J. Veg. Sci. 2, 35-46. 
Williams-Linera, G., Alvarez-Aquino, C., Hernández-Ascención, E., et al., 2011. Early successional sites and the recovery of vegetation structure and tree species of the tropical dry forest in Veracruz, Mexico. New Forest. 42, 131-148.

Willis, C.G., Halina, M., Lehman, C., Reich, P.B., Keen, A., McCarthy, S., CavenderBares, J., 2010. Phylogenetic community structure in Minnesota oak savanna is influenced by spatial extent and environmental variation. Ecography 33, 565-577.
Zermeño-Hernández, I., Toribio, M., Siebe, C., Benítez-Malvido, J., Martínez-Ramos, M., 2015. Ecological disturbance caused by agricultural land uses and its effects on tropical forest regeneration. Appl. Veg. Sci. 18, 443-455. 